\title{
Report
}

\section{Acute Otomastoiditisin Children: Clinical Presentations and Management}

\author{
Rim Bechraoui*, Mohamed Dhaha, Sana Mahfoudhi, Azza Mediouni, Jihen Marrakchi, \\ Houda Chahed, Mohamed BenAmor, Najeh Beltaief, Rim Zainine, Ghazi Besbes
}

Department of ENT and Maxillo-Facial Surgery Rabta Hospital, Tunis, Tunisia

\author{
Email address: \\ rbechraoui@yahoo.fr (R. Bechraoui) \\ ${ }^{*}$ Corresponding author
}

\section{To cite this article:}

Rim Bechraoui, Mohamed Dhaha, Sana Mahfoudhi, Azza Mediouni, Jihen Marrakchi, Houda Chahed, Mohamed BenAmor, Najeh Beltaief, Rim Zainine, Ghazi Besbes. Acute Otomastoiditisin Children: Clinical Presentations and Management. International Journal of Otorhinolaryngology. Vol. 4, No. 1, 2018, pp. 6-10. doi: 10.11648/j.ijo.20180401.11

Received: December 3, 2017; Accepted: December 25, 2017; Published: January 19, 2018

\begin{abstract}
Acute mastoiditis (AC) is a serious complication of acute otitis media (AOM) affecting, in most cases, the pediatric population. Diagnosis is usually easy in front of a retro auricular swelling associated to OM. However, this disease may cause significant and even life threatening complications beyond the tympanomastoid system such as peripheral facial nerve palsy, Bezold's abscess, meningitis, subperiosteal abscess and brain abscess. Management of AC remains controversial raging from conservative treatment in the form of IV antibiotics to more aggressive interventions such as mastoidectomy. This retrospective study represents our experience in the management of $\mathrm{AC}$ in the pediatric population. Our purpose was to review and discuss clinical presentations and main treatment modalities of AM.
\end{abstract}

Keywords: Acute Mastoiditis, Otitis Media, Antibiotic Therapy, Mastoidectomy

\section{Introduction}

Acute mastoiditis (AM) is an infectious process which involves the mastoid bone and cavities realizing a real osteitis. $0.24 \%$ of acute otitis media (AOM) are complicated by acute AM. Infants and younger children are more concerned by the disease. Although diagnosis is usually evident in front of clinical facts, management, especially mastoidectomy, is still controversial.

\section{Patients and Methods}

We retrospectively reviewed the medical data of 62 children suffering from AM, who were admitted in the ENT and cervico facial surgery department of the RABTA hospital of Tunis between the years 1990 and 2013. We included in the study children aged 16 years and younger presenting AM following chronic or acute otitis.

\section{Results}

Of the 62 children diagnosed with AM, 35 (56\%) were males and $27(44 \%)$ were females (sex ratio= 1.3$)$. The average age was 4 years with a range from 2 months to 14 years. $33 \%$ of patients were infants younger than 1 year. In medical history we noted microcytic anemia in one case, intra-uterine growth retardation in another case and one patient having had chemotherapy for malignant tumor of the clavicle. The left mastoid was concerned in 33 cases (53\%) while the right side in 29 cases (47\%). An interval between 1 and 30 days between initial symptoms and first consultation was found (average delay was 16 days).

In 45 cases (72.5\%), a first episode of AOM previous to the $\mathrm{AM}$ was found. In the other cases AM was a complication of Cholesteatoma in 9 cases (14.5\%) (congenital Cholesteatoma in 3 cases and acquired Cholesteatoma in 6 cases) and simple chronic otitis in 8 cases.

Retro auricular swelling was the chief complaint noted in 
61 cases (98\%). Otalgia, otorrhea, fever and facial palsy were found respectively in 32, 34, 51 and 2 cases (table 1).

Table 1. Clinical presentations.

\begin{tabular}{lll}
\hline Symptom & Number of patients & Rate \\
\hline Retro auricular swelling & 60 & $98 \%$ \\
Otorrhea & 32 & $51.6 \%$ \\
Otalgia & 34 & $54.8 \%$ \\
Fever & 51 & $82.2 \%$ \\
Facial palsy & 2 & $3.2 \%$ \\
Headache & 2 & $3.2 \%$ \\
Vertigo & 1 & $1.61 \%$ \\
\hline
\end{tabular}

In all cases general condition was preserved. Retro auricular swelling which was noted in 62 cases was extended to the neck in 2 patients. It was inflammatory and fluctuant in 36 cases $(58 \%)$ and limited to a simple mastoid tenderness in the other cases (Figure 1). Spontaneous cutaneous fistula was noted in 2 children $(3.2 \%)$.

Retro auricular swelling was found in $97 \%$ of cases. When performing otoscopy, several pathological aspects were objectified in external auditory canal in $91 \%$ of cases (table 2 ) and in the tympanic membrane in $95.16 \%$. Tympanic membrane perforation was noted in 12 cases. It was central in 8 cases and marginal with Cholesteatoma in the other 4 cases. One patient in the series had a parotid abscess. The neurological examination found 2 patients with peripheral facial palsy and one patient with clinical presentation suggesting intracranial hypertension.
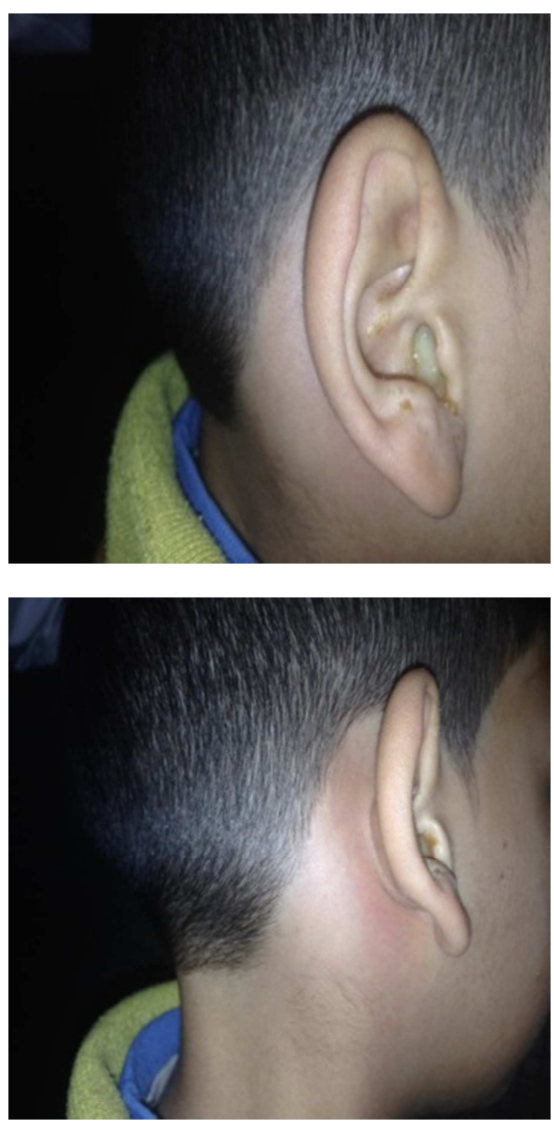

Figure 1. AOM complicated with AM and Bezold abscess.
Table 2. State of the external auditory canal.

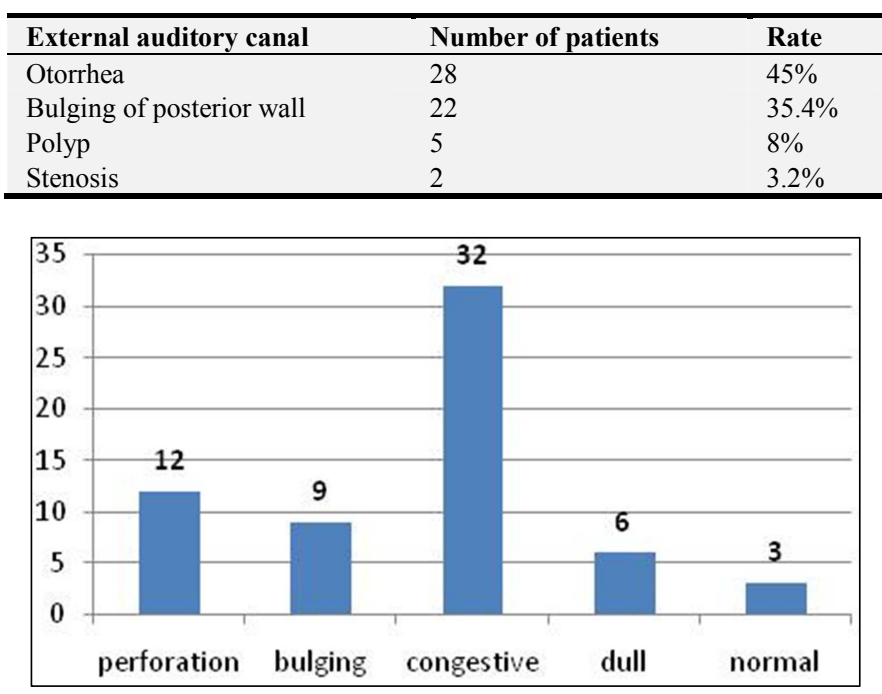

Figure 2. State of the eardrum.

All patients have benefited of a blood count. Hyperleukocytosis was noted in $84.6 \%$ of cases. CRP level was evaluated in 18 cases. It was positive in 10 cases with an average of $45 \mathrm{mg} / 1$.

30 patients $(49 \%)$ have benefited of CT scan of the brain and temporal bone confirming the diagnosis of acute otomastoiditis. Intracranial complications were noted in 2 patients. It consisted in extradural and subdural abscesses. In these 2 cases AM followed an episode of AOM. CT scan findings are summarized in table 3 . Figure 3 illustrates a retro auricular collection.

Table 3. CT scan of temporal bone and brain findings.

\begin{tabular}{lll}
\hline & Number & Rate \\
\hline External mastoid bone cortical lysis & 21 & $70 \%$ \\
Subcutaneous collections & 27 & $90 \%$ \\
Lateral sinus thrombosis & 4 & $13.33 \%$ \\
Extradural abscess & 1 & $3.33 \%$ \\
Subdural abscess & 1 & $3.33 \%$ \\
Parotid gland abscess & 1 & $3.33 \%$ \\
Bezold mastoiditis & 2 & $6.6 \%$ \\
Cellulites of temporal and occipital regions soft & 1 & $3.3 \%$ \\
tissues & 1 & \\
\hline
\end{tabular}
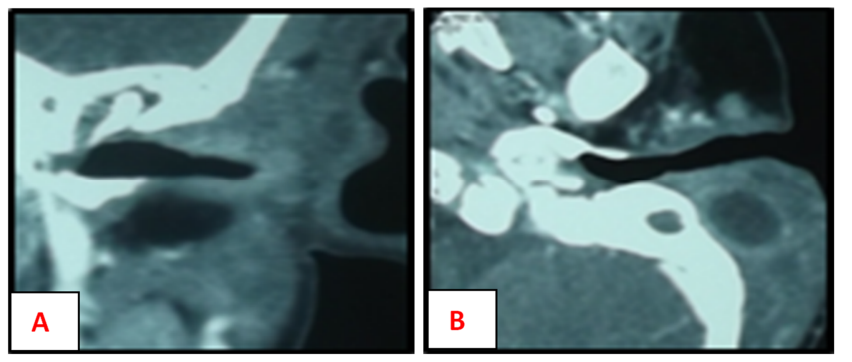

Figure 3. CT scan of temporal bone axial section (A) and coronal section (B): retro auricular collection.

Bacteriological samples were performed in 20 patients. Theses samples were positive in 8 cases. Staphylococcus aureus was the most frequent pathogen ( 5 cases) followed by 
Streptococcus pneumonia ( 2 cases) and Proteus Mirabilis in one case.

IV antibiotics were used in all cases. It consisted in a bitherapy in the majority of cases (49 patients). Monotherapy was administrated in 10 cases (Table 4 ).

Table 4. Antibiotics

\begin{tabular}{lll}
\hline Molecule & Number & Rate \\
\hline Amoxicillin + clavulanic acid & 10 & $16 \%$ \\
Cefotaxime + fosfomycin & 35 & $56.45 \%$ \\
Amoxicillin + clavulanic acid + gentamycin & 3 & $4,8 \%$ \\
Cefotaxime + amikacin & 10 & $16 \%$ \\
Peni G + gentamycin & 4 & $6,4 \%$ \\
\hline
\end{tabular}

Patients were divided in 4 groups depending on the management modalities.

Group 1: antibiotics only:

27 patients (43\%) were treated by IV antibiotics (7 subperiosteal abscesses and 20petrositities). Treatment was ensured for a period varying from 2 weeks to one month. IV treatment was administrated for 10 days. Mean hospital stay was 8 days.

Group 2: antibiotics associated to flattening of subperiosteal abscess:
This group counts 15 patients (24\%). Flattening of the abscesses was performed for all patients. Bacteriological samples were systematic. Antibiotic therapy was ensured for a period of 2 weeks to 1 month. IV treatment was administrated for 10 to 15 days. Mean hospital stay was 9 days.

Group 3: antibiotics associated to flattening of subperiosteal abscess and mastoidectomy:

This group counts 7 patients. Flattening of the abscess was performed since admission of the child. Mastoidectomy was then done within a time limit from 2 to 11 days with an average of 6 days. Mean hospital stay was 21 days (10 to 43 days).

Group 4: antibiotics associated to mastoidectomy:

This group counts 13 patients (21\%). Time limit between starting antibiotics administration and mastoidectomy varied from 1 to 20 days with an average of 3 days. Mean hospital stay was 12 days ( 7 to 30 days).

In the third and fourth group, mastoidectomy was done from the start when AM was associated to Cholesteatoma or in complicated forms (facial palsy, brain abscess). The same intervention was done secondarily when antibiotics (alone or associated to flattening) were not efficient after 48h (table 5).

Table 5. Therapeutic modalities.

\begin{tabular}{lllll}
\hline & \multicolumn{2}{l}{ Conservative approach } & Surgical treatment & Total \\
\hline & Antibiotics only & Antibiotics+abscess flattening & $\begin{array}{l}\text { Mastoidectomy from the } \\
\text { start }\end{array}$ & $\begin{array}{l}\text { Mastoidectomy after failure of } \\
\text { conservative approach }\end{array}$ \\
\hline Petrositis & 20 & - & 6 & - \\
Subperiosteal abscess & 7 & 15 & 7 & 7 \\
\hline
\end{tabular}

Eight patients underwent a canal wall down mastoidectomy whereas 1 patient underwent a canal wall up mastoidectomy. The facial nerve was bare in its $2^{\text {nd }}$ portion in one case and in the second genu in another case. Covering by the temporal aponeurosis was performed in both cases. Mastoidectomy was done secondarily in one case after drainage of extradural abscess by neurosurgeons.
Immediate outcome was favorable in 60 cases with ear drying and regression of retro auricular swelling. 2 patients presented wound healing problems that responded well to antibiotic and local care.

Median follow-up was 24 months ( 2 months to 10 years). 43 patients were seen at the consultation beyond one month. 5 among them presented a relapse of their disease (table 6).

Table 6. Cases with unfavorable outcomes.

\begin{tabular}{lllll}
\hline & Case1 & Case2 & Case3 & Case4 \\
\hline Etiology & AOM & AOM & AOM & Cholesteatoma \\
\hline Group & $\mathbf{2}$ & $\mathbf{1}$ & $\mathbf{4}$ & $\mathbf{4}$ \\
\hline \multirow{2}{*}{ Relapse } & $\begin{array}{l}\text { Otomastoiditis episode } \\
\text { after 7 months }\end{array}$ & $\begin{array}{l}\text { Otomastoiditis } \\
\text { episode after 1 year }\end{array}$ & $\begin{array}{l}\text { Otomastoiditis episode } \\
\text { after 10 months }\end{array}$ & $\begin{array}{l}\text { Recurrence of Cholesteatoma and } \\
\text { meningeal prolapse }\end{array}$ \\
& Antibiotic+abscess & Otorrhea after 4 \\
Treatment & mastoidectomy & mastoidectomy & mastoidectomy \\
flattening & favorable & favorable & Favorable \\
\hline
\end{tabular}

\section{Discussion}

AM prevalence has considerably decreased since the wide use of antibiotics. However, a recent increase of the incidence has been reported due to the immergence of resistant pneumococcus strains with decreased sensitivity to Penicillin $[1,2]$. Young children are more concerned with AM especially between the second and third years of life [1,3]. Middle age in our series was 4 years with incidence peaking in infants younger than 2 years $(47.7 \%)$. Generally, AM is a complication of AOM [4] it could also follow and infectious episode of Cholesteatoma.

Clinical presentation depends on age and the disease progression $[5,6]$. retro auricular swelling is a constant sign with an important clinical value. The most reliable otoscopic findings are otorrhea, posterior wall fall and bulging tympanic membrane.

CT scan of temporal bone and brain is the reference investigation for AM diagnosis and complications. According 
to some authors it should be systematic [3]. For others, it should only be performed in unusual or complicated forms [1, 7].

According to recent studies $[3,8]$, streptococcus pneumoniae is the most common pathogen responsible for AM $(29 \%$ to $65 \%)$. Emergence of resistant and decreased-sensitivity to penicillin strains (reaching 50\%) has been reported.

AM management in children is controversial [4]. Therapeutic approaches vary from center to center due to absence of randomized controlled studies. Different therapeutic modalities exist: antibiotics, abscess flattening and mastoidectomy. The choice depends on the disease progression, etiology and presence of complications.

Antibiotics are essential in the management regardless the stage of the disease. Recommendations concerning the choice of antibiotic therapy differ with the region. According to the American Academy of Otolaryngology [9], an association between a third-generation cephalosporin and vancomycin should be considered as first-line therapy. Others recommend an association between third-generation cephalosporin and metronidazole in order to cover anaerobic pathogens [10]. This probabilistic therapy should be adjusted to bacteriological findings.

As soon as there is clinical and biological ameliorations (long-lasting apyrexia and regression of pain, local signs and biological inflammatory syndrome, switching to oral therapy is permitted. The total duration of antibiotic therapy is at least 12 to 15 days and 5 weeks at least in case of association of anaerobic pathogens $[10,11]$. In our series, association of cefotaxime and fosfomycin was the first-line therapy in $56 \%$ of cases.

Most authors have conservative attitude in front of none complicated AM with recovery rates reaching $61 \%$ to $96 \%$ [3, $4,6,7]$. In majority of cases, petrositis respond well to well-guided Antibiotic therapy and paracentisis [12, 13]. Subperiosteal abscess without complication should be flattened or aspirated.

Indications of mastoidectomy are not well established. Currently, conservative approach is more retained (4). Most authors keep surgery for complicated cases, Cholesteatoma, anaerobic infection and absence of amelioration within 48 to 72 hours of well-guided antibiotics therapy [1, 14]. Mastoidectomy was performed in our series in 13 cases $(21 \%)$; Cholesteatoma in 9 cases, in 4 complicated cases and in 7 others after failure of conservative approach.

Complicated forms are usually treated with IV antibiotics, paracentisis with or without trans-tympanic tube and mastoidectomy $[12,13]$. Facial palsy could respond well to conservative treatment without needing mastoidectomy. Facial nerve decompression and corticoids are not recommended [13].

Intracranial complications should be treated with prolonged IV antibiotic therapy (4 to 6 weeks) in association to mastoidectomy. Anticoagulation is not indicated in management of lateral sinus thrombosis according to most authors $[15,16]$. According to Attlmayr and colleagues, the improvement in imaging technologies and aids may explain the apparent increase of intracranial complications [17].
Outcome of AM depends on treatment delay and progression of the disease $[12,13]$. Relapses are rare. Intracranial complications could be provider of permanent neurological defects in some children [13].

According to a recent study, despite the introduction of pneumococcal vaccines the pediatrics hospitalization rate for AM did not decline between 2000 and 2012 [18]. However, according to the same authors, there was a decline in the hospitalization rates for the children between 0 and 2 years in the years between 2009 and 2012 [18]. This could reflect a protective benefit of pneumococcal vaccination.

\section{Conclusion}

AM is a classic complication of AOM. Prognosis is good under some circumstances: well-guided antibiotic therapy, paracentisis and aspiration of subperiosteal abscess were needed. Mastoidectomy should be saved to complicated forms, Cholesteatoma or in case of failure of conservative approach with $48 \mathrm{~h}$ as time limit.

\section{References}

[1] Couloigner V, Pierrot S, Manach Y. Maigues de l'enfant. EncyclMédChir otorhinolaryngologie 2008, 20-090-A-10, 11p.

[2] Urwald O, Metrol J-C, Legros M. Les mastoïdites aigues de l'enfant: A propos de 38 cas. Ann Otolaryngol Chir Cervicofac 2002; 119: 264-270.

[3] Ana I, Eguía N, Conejo-Moreno D, De-La-Mata-Franco G, Clemente-Garcíaa A. Acute mastoiditis in the pneumococcal vaccine era. Acta Otorrinolaringol Esp 2011; 62: 45.

[4] Psarommatis IM, Voudouris C, Douros K, Giannakopoulos P, Bairamis T, Carabinos C. Algorithmic management of pediatric acute mastoiditis. Int. J. Pediatr. Otorhinolaryngol 2012; 76; 791-796.

[5] Leskinen K. Complications of acute otitis media in children. Curr Allergy Asthma Rep 2005; 5: 308.

[6] Groth A, Enoksson F, Hultcrantz M, Stalfors J, Stenfeldt K, Hermansson A. Acute mastoiditis in children aged $0-16$ years: A national study of 678 cases in Sweden comparing different age groups. International Journal of Pediatric Otorhinolaryngology 2012; 76: 1494-1500.

[7] Tamir S, Shwartz Y, Peleg U, Shaul C, Perez R, Sichel J-Y. Shifting trends: mastoiditis from a surgical to a medical disease American. Journal of Otolaryngology-Head and Neck Medicine and Surgery 2010; 31: 467-471.

[8] Roddy MG, Glazier SS, AgrawalD. Pediatricmastoiditis in the pneumococcal conjugate vaccine era: symptom duration guides empiric antimicrobial therapy. Pediatr Emerg Care 2007; 23: 779-784.

[9] Hentgen V, Lorrot $M$, Haas $H$, Haas $H$, Cohen $R$. Antibiothérapie des infections ORL sévères du nourrisson et de l'enfant: mastoïdites aiguës. Arch pediatr 2013; 20: e14-9.

[10] Sharland M. Acute Mastoiditis. Manual of childhood infections-the Blue Book. Oxford University Press. The Royal College of Paediatrics and Child Health 2011; p. 240. 
[11] Grimprel E, Hentgen V, Lorrot M, Haas H, Cohen R. Antibiothérapie des infections ORL sévères du nourrisson et de l'enfant: propositions thérapeutiques du Groupe de pathologie infectieuse pédiatrique (GPIP) de la Société française de pédiatrie. Arch Pediatr. 2013; 20: e14-9.

[12] Anderson KJ. Mastoiditis. Pediatr Rev 2009; 30: 233-4.

[13] Wald ER. Acutemastoiditis in children: Treatement and prevention. In: Up to date, Post, TW (Ed), Up To Date, MA, 2013.

[14] Zanetti D, Nassif N. Indications for surgery in acute mastoiditis and their complications in children. Int $\mathrm{J}$ Pediatr Otorhinolaryngol 2006; 70: 1175-82.
[15] Viswanatha B, Naseeruddin MSK. Lateral Sinus Thrombosis in Otology: a Review. Medit J Hemat Infect Dis. 2010; 2 (3): e2010027.

[16] Singh B. The management of lateral sinus thrombosis. J LaryngolOtol 1993; 107: 803-8.

[17] Attlmayr B, Zaman S, Scott J, Derbyshire SG, Clarke RW, De S Paediatric acute mastoiditis, then and now: is it more of a problem now? The Journal of laryngology and otology. 2015; 129 (10): 955-9.

[18] Tawfik KO, Ishman SL. Pediatric acute mastoiditis in the era of pneumococcal vaccination. 2017. 